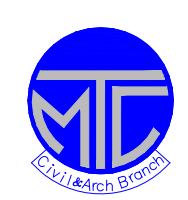

ICCAE

Military Technical College

Kobry Elkobbah,

Cairo, Egypt 7th International Conference

On Civil \& Architecture

Engineering

\title{
OPTIMUM DESIGN FOR SANDWICH PANELS WITH METALLIC HEXAGONAL HONEYCOMB CORE SUBJECTED TO BLAST LOADS
}

\author{
EL-FAYAD * H. M, ABDEL-WAHAB ** M. M, FARAG *** H. M. \\ And El-ASHAAL **** A. A
}

\begin{abstract}
In the last decade, design and optimization of structures subjected to blast loads got the attention of many researchers. The great threaten of terrorizing activates; in addition to instability in different areas of the world drive these researches. Sandwich panels give an optimum and proven tools to handle problems related to design and analysis of such structures. The present work focuses on increasing the blast resistance of steel sandwich panels. These panels can be applied on defense works, homeland security, banks and civilian industries intended to minimize the effects of accidental explosions. Sandwich constructions with metallic hexagonal honeycomb core are utilized in this research due to its high specific strength and stiffness with minimum weight. Minimizing the weight of the metallic hexagonal honeycomb core is regarded as the objective function of the optimization process that was tested under blast loads resulted from detonating $100 \mathrm{~kg}$ of TNT at 5-m stand-off distance. The strength and stiffness of honeycomb core panels were evaluated based on constraint condition of strength and deformation. A response surface analysis was performed on the parameters affecting the allowable global displacement by simplifying the explosion pattern and developing a response limits adapting TM5 requirements [1]. F.E. technique was utilized to handle the numerical configuration of the studied cases. ANSYS code [2] proved the environment for processing the analysis and optimization. The proposed approach suggested to control the parametric optimization analysis succeeded to provide an optimum configuration for the metallic hexagonal honeycomb core structure under blasting condition.
\end{abstract}

\section{KEYWORDS}

Sandwich panels, Honeycomb, Optimization. 
* Ph. D. Applicant, Syrian Armed Forces.

** Brig. D, Military Technical College, Egyptian Armed Forces, Egypt.

*** Brig. D, Military Technical College, Egyptian Armed Forces, Egypt.

$\star \star \star \star$ Professor. Director of Construction Research Institute, National Water Research Center, Egypt.

\section{NOMENCLATURE}

$E_{f} \quad$ Modulus of elasticity

$E_{e q}$ Equivalent modulus of elasticity

$G_{f} \quad$ Shear modulus

$G_{e q} \quad$ Equivalent shear modulus

$H$ Central distance between front and back faces.

$H_{1} \quad$ Sandwich panel construction depth

$h_{c} \quad$ Hexagonal core depth

$I_{f} \quad$ Inertia of the facing skins

$S$ Cell hexagonal size

$T_{C} \quad$ Hexagonal wall thickness
$T_{1} \quad$ Back plate thickness (face1)

$T_{2} \quad$ Front plate thickness (face2)

$T_{3} \quad$ Frame thickness

$T_{c} \quad$ Hexagonal core wall thickness

$t_{f} \quad$ Face thickness

$t_{e q} \quad$ Equivalent plate thickness

$\rho_{c} \quad$ Material density

$\rho_{c a}$ Average density of honeycomb cores

$\rho_{c t}$ Theoretical hexagonal cell core density

\section{ABBREVIATIONS}

TM5 : Technical manual

F.E.M : Finite element method

APDL : ANSYS Parametric Design Language
DOE : Design of Experiments

SEQV : StresS

\section{INTRODUCTION}

Sandwich construction with hexagonal honeycomb core is the most widely used construction in sandwich construction. It is a structural element which consists of thinwall elements. The selection of the optimum parameters of sandwich construction as shown in figures (1) and (2) is an important subject. The effect of the sandwich thickness on stiffness and strength is shown in figure (3). 3D sketch of the steel hexagonal honeycomb sandwich panel is shown in figure (4). The density ratio of the honeycomb core is considered. The size of the honeycomb cell " $\mathrm{S}$ " is taken constant in this paper; hence four parameters $\left(H, T_{1}, T_{2}\right.$, and Tc) are studied.

Sandwich construction is mainly used to obtain specific strength and stiffness, i.e. to obtain minimum weight of structural elements under the premises of design requirements. Since they have a high strength to weight ratio and excellent energy absorption capabilities under dynamic loading conditions, the core of the sandwich 
structure can sustain large deformations under a constant load, enabling it to absorb energy as shown in the Figure (5). More than $43 \%$ of internal energy propagated in all components of the panel at time $9.028 \mathrm{~ms}$ was absorbed by the core. The use of sandwich panels might be an effective method to mitigate the damaging effects of blast loading on structural buildings.

This paper will discuss the optimum design of sandwich parameters; it will be concerned with how to select the four parameters mentioned above in order to minimize the sandwich weight considering the requirements of the design of steel sandwich panel structure subjected to blast loads. Panel and one unit strip of the panel were analyzed using APDL (ANSYS Parametric Design Language) [2].

\section{METHODOLOGY}

The corrugated process is essentially main method to make honeycomb out of flat material, the corrugated process illustrated in Figure (6) is used for metallic cores of higher density [5]. For this process, the web material is corrugated through a set of rollers. Welding is then applied to the nodes, and the corrugated sheets are then stacked on top of each other. Figure (7) represents a schematic concept of the equivalent single skin approach. The moment of inertia of the facing skins for a honeycomb sandwich panel can be calculated as follows, see [4], [8]:

$$
I_{f}=\frac{H_{1}^{3}-h_{c}^{3}}{12} b
$$

Where: $b$ is the width of the panel.

The virtual area of a unit honeycomb core at the cross section parallel to the facing skin plane is given by:

$$
A=L . W
$$

The average density of honeycomb core can be obtained from:

$$
r_{c a}=\frac{8 d T_{C}}{A} \times r_{c} @ \frac{8}{3 \sqrt{3}} \times \frac{T_{C}}{d} \times r_{C}
$$

The theoretical hexagonal cell core density $\left(r_{c t}\right)$ can be expressed in terms of cell size $(S)$, Hexagonal wall thickness $\left(T_{c}\right)$ and material density $\left(\Gamma_{C}\right)$ as:

$$
r_{c t}=\frac{3 T_{C}}{S} r_{C}
$$

The honeycomb sandwich panel can be replaced by the equivalent single skin plate, using two methods. These methods are the equivalent rigidity method and the equivalent weight method. In the equivalent rigidity method, plate thickness and elastic modulus are defined such that the rigidity of the sandwich panel is equivalent to that of the single skin panel. In the equivalent weight method, dimensions of the 
equivalent single skin panel are defined so that the structural weight is equal. The equivalent material properties of the single skin panel with the equivalent rigidity can be estimated from the following equations. The rigidity of the panel with equal facing skin thickness is considered separately for in-plane tension, bending and shear:

In tension:

$2 t_{f} E_{f}=t_{e q} E_{e q}$

In bending:

$\frac{1}{12}\left[\left(h_{c}+2 t_{f}\right)^{3}-h_{c}^{3}\right] E_{f}=\frac{1}{12} t_{e q}^{3} E_{e q}$

In shear:

$2 t_{f} G_{f}=t_{e q} G_{e q}$

The values $t_{e q}, E_{e q}$ and $G_{e q}$ can be obtained by solving the above equations as follows:

$$
\begin{aligned}
& t_{e q}=\sqrt{3 h_{c}^{2}+6 h_{c} t_{f}+4 t_{f}^{2}} \\
& E_{e q}=\frac{2 t_{f}}{t_{e q}} E_{f} \\
& G_{e q}=\frac{2 t_{f}}{t_{e q}} G_{f}
\end{aligned}
$$

On the other hand, the equivalent plate thickness $t_{e q}$ of the single skin plate based on equal weights may be calculated from:

$$
L \cdot W \cdot t_{e q} \cdot r_{f}=L \cdot W \cdot 2 t_{f} \cdot r_{f}+L \cdot W \cdot h_{c} \cdot r_{c a}
$$

Resulting in:

$$
t_{e q}=\frac{2 t_{f} r_{f}+h_{c} \cdot r_{c a}}{r_{f}}
$$

The elastic and shear moduli of the equivalent single skin panel are assumed to equal those of facing skin materials, namely

$$
E_{e q}=E_{f}, G_{e q}=G_{f}
$$




\section{DESIGN CRITERIA}

The honeycomb sandwich panel is designed to protect personnel from exterior loading. Leakage into the structure is permitted but the maximum end rotation of any member is limited to $2^{\circ}$ as shown in figure (8), since panic hardware must be operable after an accidental explosion [1].

\section{SANDWICH PANELS}

\subsection{CASE STUDY}

The target of this study is to minimize the weight of the sandwich panel subject to a pressure-time loading, figure (9), which results from detonating $100 \mathrm{~kg}$ of TNT at $5 \mathrm{~m}$ stand-off distance applied as an equivalent pressure on the front plate of the panel. The dimensions of the sandwich panel for this study was $(140 \mathrm{~cm} \times 260 \mathrm{~cm})$, and consists of two plates wrapped the honeycomb steel core as shown in Figure (4). The boundary condition was simply supported on four sides. All the elements are modeled as a shell 181 [2] which is suitable for analyzing thin to moderately-thick shell structures. It is a 4-node element with six degrees of freedom at each node: translations in the $\mathrm{x}, \mathrm{y}$, and $\mathrm{z}$ directions, and rotations about the $\mathrm{x}, \mathrm{y}$, and $\mathrm{z}$-axes. This shell element is well-suited for linear, large rotation, and/or large strain nonlinear applications. Change in shell thickness is accounted for nonlinear analyses. The model was built as a parametric model of a sandwich symmetry unit strip with metallic hexagonal honeycomb core, using $\mathrm{T}_{1}, \mathrm{~T}_{2}, \mathrm{~T}_{\mathrm{c}}, \mathrm{H}, \mathrm{S}$ and load as the parameters. All other dimensions and input values are fixed. The following material properties are used for this analysis: density $=7850 \mathrm{~kg} / \mathrm{m}^{3}$, Young's modulus $=200 \mathrm{GPa}$, Poisson's ratio $=0.3$, yield stress $=310 \mathrm{MPa}$.

\subsection{VALIDATION}

Jeom Kee Paik et all, [4] showed that when the core height is relatively small the equivalent weight method as mentioned in item (2), provides better results. While for the sandwich panels with a higher honeycomb core, the equivalent rigidity method may predict the ultimate compressive strengths more reasonably. In addition, Jeom Kee Paik et all, [4] tested specimens of aluminum honeycomb sandwich panels and analyzed the bending behavior and the shear effects of honeycomb core.

In order to validate the finite element model, the ANSYS solution time-deflection curve is compared with the actual AUTODYN [3] time-deflection curve (Figure (10)) for depth $\mathrm{H}=100 \mathrm{~mm}$. The result shows excellent correlation with the AUTODYN result. The slight discrepancy is due to the error caused by the difference between the methods of solution used in each package and by the material model used to define the post yield property of the parts. However, this model is sufficient to achieve the purpose of this research, which is to determine the load distribution 
within the sandwich panel and the effect of geometric non-linearity on this load distribution. In this study the equivalent weight method is used. Figure (10) shows that this method is not appropriate for the bending behavior in the panel. In this study, one of their specimens (3PB2, b=100mm, L=500 mm) [4], was modeled using ANSYS software and the results were compared with the experimental work [4]. Figures (11) and (12) show the deformed shape obtained in the experimental work and the F.E.analysis respectively. The maximum deflection in F.E was $(3.792 \mathrm{~mm})$, while the maximum deflection in the experimental work was $(3.8 \mathrm{~mm})$. This comparison show the capability of the proposed F.E model to simulate the honeycomb problems.

\subsection{OPTIMIZATION STUDY}

In the detailed design phase of an engineering design process, the main task is to obtain the best design that meets the design requirements with a minimum cost (weight). This is an iterative process, where an initial model is first chosen and evaluated to fulfill the design requirements. After interpretation, a refined model is designed and evaluated. This iterative process, which involves tasks as design, evaluation, and redesign, is repeated until a sufficiently good design is reached. The model parameters can be changed by the optimization routine as design variables. Allowable stress and deflection limits are referred to as constraint variables.

In ANSYS software [2], the terms "objective function" and "design variables" are used. Constraint variables are referred to as a "state variable". A first order optimization method was utilized, i.e. the values for the optimization parameters as well as their derivatives were evaluated in each iteration in order to determine the search direction. The method is rather accurate but is computationally demanding. Design variables, state variables and objective function are shown in Table 1.

For reducing the computational process, one strip with width equal to size of the core cell was modeled and takes advantage of symmetry. The optimization procedure is presented in Figure (13). The maximum stress before optimization was equal to 468.06 $\mathrm{MPa}$ and in the final loop of optimization was $275.61 \mathrm{MPa}$, while the maximum deflection in the initial model was 0.48390E-01 $\mathrm{m}$ and in the final loop of optimization was equal to $0.35754 \mathrm{E}-01$. The results of optimization show reduction ratios in stress and deflection about (41.12\%) and (26.11\%), respectively. It is clear from figures (14) to (18), that the solution has converged only after four iterations to achieve the requirements due to the logician selection of the values of the initial design variables in the initial model. Figures (14) to (18) show the convergences of the design objective, variables and constraints. It can be noted from Figure (14) the clear decrease in deflection with increasing $(\mathrm{H})$. Figure (15) shows the clear increase in the depth $(\mathrm{H})$ with reduction in stress that can be observed which indicates a significant improvement in the objectives of these design cases. Figures (16) and (17) show variation on $T_{1}, T_{2}$ and $T_{c}$ versus iteration number. Total volume is successfully controlled within the constraint as the iterations progress as shown in Figure (18).

\subsection{RESPONSE EVALUATION OF THE SANDWICH PANEL}


Figures (20) and (21) illustrate the distribution for the deflection and stresses, respectively that propagate in the total panel for the initial model at time $t=6.217 \mathrm{~ms}$, the time at which the maximum displacement has occurred. Figure (22) illustrates the distribution for the deflection that propagates in the hexagonal honeycomb core of the panel at the same time. The maximum deflection at the center of the panel in the initial model was $0.043401 \mathrm{~m}$ while it was $0.04839 \mathrm{~m}$ in the initial unit strip with same parameters. The difference was $11.5 \%$, since the optimization study was on the unit strip for reducing the calculating time. Figure (23) illustrates the displacement versus time before and after optimization that propagates in the node at which the maximum displacement has occurred. Figure (24) shows the deformation for the unit strip before (Left) and after optimization (Right). From Figure (19) it can be noted the deformation at the ends of the core (near the support) due to shear stress at the support.

DOE is a technique based on DesignXplorer Environments used to determine the location of sampling points. Such that the space of random input parameters is explored in the most efficient way, or obtain the required information with a minimum of sampling points. Usually the function $y=F(x 1, x 2, x 3, \ldots)$ is a polynomial or some other well-defined relationship between a variable of interest, $y$, and a set of independent variables, $x 1, x 2, x 3, \ldots$, which forms the response surface model of $y$. The response surface plots, as shown in Figures (25) to (30) are the representation of the physical behavior of a structure in terms of its independent variables.

The purpose of a response surface is to gain an understanding of the impact of uncertainties associated with the input parameter of the design, and useful in selecting the honeycomb parameters namely, sandwich panel construction depth, hexagonal wall thickness, back plate thickness, front plate thickness, for the response of stresses and deflection. Figure (25) shows the interaction between (Tc, $\mathrm{H})$ that when $\mathrm{Tc}$ increases the deflection decreases, similarly when $\mathrm{H}$ increases the deflection decreases. The max deflection is obtained when $\left(T_{C}, H\right)$ are both minimum. Figure (26) shows the interaction between $\left(T_{1}, H\right)$, which reveals that when $T_{1}$ increases the deflection decreases. The max deflection is obtained when $\left(T_{1}, H\right)$ are both minimum. Also when the $\left(T_{1}\right)$ decreases and $(H)$ increases, the deflection decreases. This result means that the parameter $(H)$ has the dominant effect on deflection response. Figure (27) shows the interaction between (loads, $\mathrm{T}_{2}$ ) versus deflection. Figure (28) shows the interaction between (loads, $\mathrm{T}_{\mathrm{c}}$ ) versus deflection. Figure (29) shows the interaction between $\left(H, T_{c}\right)$ versus stress. It is clear that when $(H)$ increases the stress decreases, similarly when $\left(T_{c}\right)$ increase the stress slowly increases. Figure (30) shows the interaction between (load, $T_{c}$ ) versus stress. As $\left(T_{c}\right)$ increases the stress decreases, similarly when (load) increases the stress increases. The maximum stress is obtained with minimum of $\left(T_{c}\right)$ and maximum of load. 


\section{CONCLUSION}

1. The response of steel sandwich panel under the blast load can be simulated using ANSYS software [2], it has the advantage, that it needs fewer hypotheses, thus it has higher analysis precision, compared to the common analysis method for individual hexagonal honeycomb core.

2. Response analysis was performed on the sandwich hexagonal honeycomb core. Surface response plots were generated and the effects of parameters, namely, sandwich panel construction depth, hexagonal wall thickness, back plate thickness, front plate thickness, for stress and deflection were discussed clearly.

3. Surface response, helps the designer to predict the logician selection of the initial design variables values in the initial model, to achieve rapidly the design optimization requirements for the sandwich panels to safe time and effort.

4. The transient response can be achieved using ANSYS with dynamic loads, which can be used to determine the critical sections of the steel sandwich panels affected by the blast loads to evaluate the mechanical response of steel sandwich panels. The method, combined FEA with dynamics analysis, is of great significance for predicting response of structure and for optimization in design stage.

5. Honeycomb sandwich structures with hexagonal core are recommend for protective structures due to the high energy absorption of the core.

\section{REFERENCES}

1. TM5,"Structures to Resist The Effects of Accidental Explosion", USA (1990).

2. ANSYS "Theory Reference manual", ANSYS Inc.

3. Manual for AUTODYN software Agency of Century Dynamics Company (2003).

4. Jeom Kee Paik, Anil K. Thayamballi, Gyu Sung Kim, "The Strength Characteristics of Aluminum Honeycomb Sandwich Panels", Pusan National University, south Korea (1999).

5. Jeffrey Rudd, "Compressive Strength To Weight Ratio Optimization Of Composite Honeycomb Through Addition of Internal Reinforcements", Akron University (2006).

6. S. D. Rajan, "Introduction to Structural Analysis \& Design", Arizona State University, John Wiley \& Sons inc., ISBN 0-471-31997-X,(2000).

7. HexWebTM Honeycomb Sandwich Design Technology. December 2000. Publication No. AGU 075b. Hexcel Composites, Duxford, United Kingdom.

8. Kaneko Y, Takeuchi K. Design and Construction of a Seawater Survey Ship Built using Aluminum Honeycomb Banels. In: Proceedings of the Second 
International Conference on Fast Sea Transportation, vol. 1, Yokohama (Japan), December 1993:449-460.

Table 1. Design variables, state variables and objective function.

\begin{tabular}{|c|c|c|c|c|}
\hline Item & Type & $\begin{array}{c}\text { LOWER } \\
\text { LIMET }\end{array}$ & $\begin{array}{c}\text { UPPER } \\
\text { LIMET }\end{array}$ & TOLERANCE \\
\hline $\mathrm{H}$ & $\mathrm{DV}$ & 0.15 & 0.30 & 0.001 \\
\hline $\mathrm{T}_{\mathrm{c}}$ & $\mathrm{DV}$ & 0.001 & 0.008 & 0.001 \\
\hline $\mathrm{T}_{1}$ & $\mathrm{DV}$ & 0.01 & 0.03 & 0.001 \\
\hline $\mathrm{T}_{2}$ & $\mathrm{DV}$ & 0.01 & 0.03 & 0.001 \\
\hline Stress & $\mathrm{SV}$ & $2.79 \mathrm{E}+8$ & $3.41 \mathrm{E}+8$ & $6.2 \mathrm{E}+5$ \\
\hline Deflection & $\mathrm{SV}$ & 0.02 & 0.037 & 0.001 \\
\hline Volume & $\mathrm{OBJ}$ & - & - & 0.0009 \\
\hline
\end{tabular}

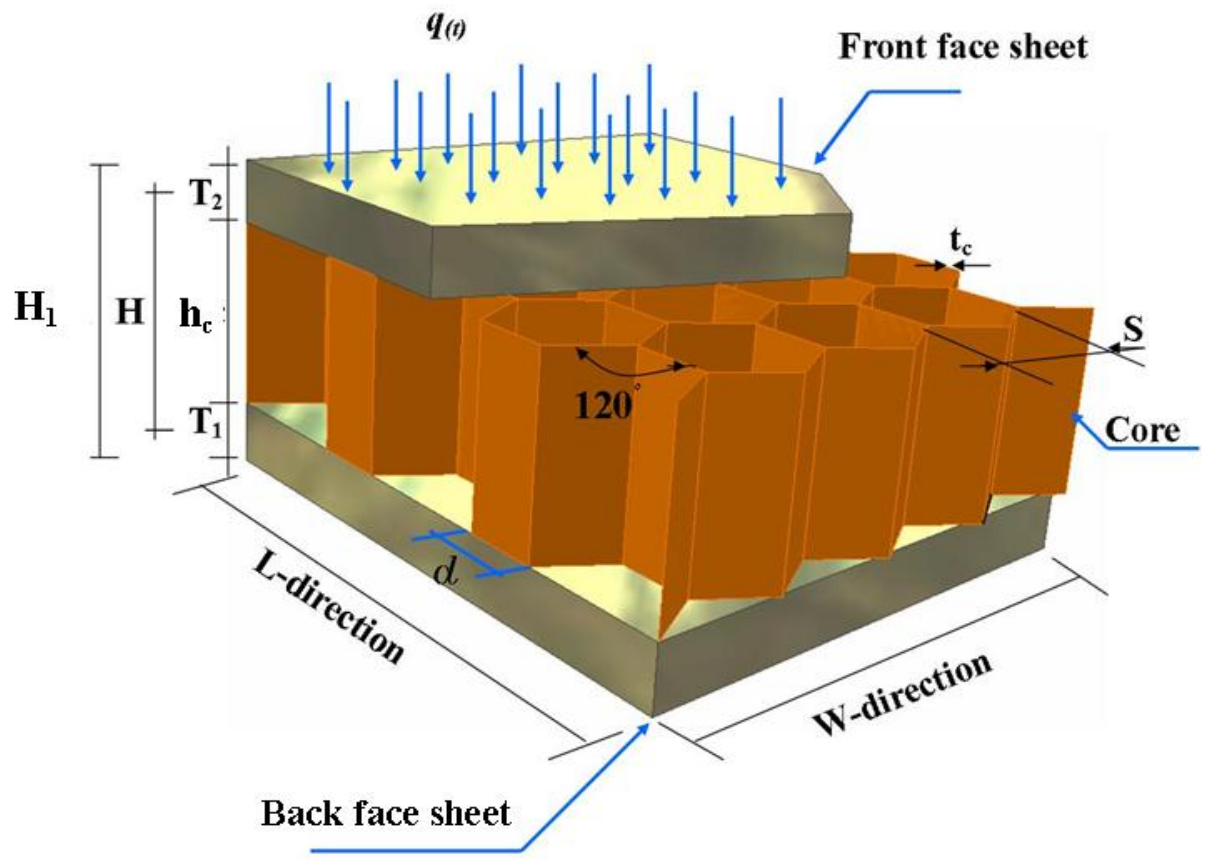

Figure (1): Geometric dimension form hexagonal honeycomb panel.

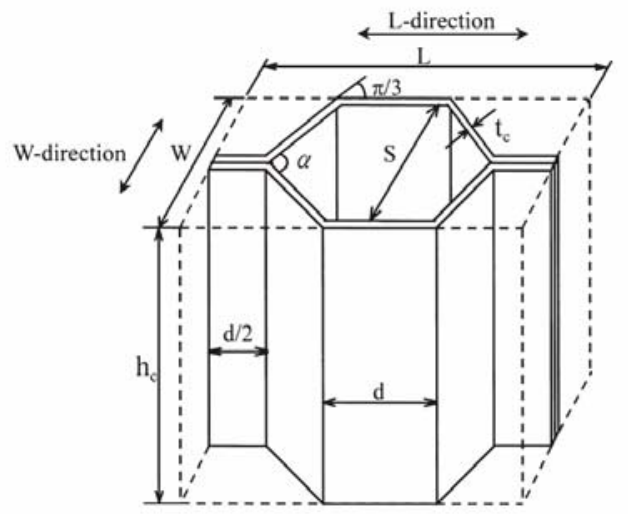

Figure (2): A honeycomb-core unit.[4]. 


\begin{tabular}{|l|l|}
\hline MS2 & 10 \\
\hline
\end{tabular}

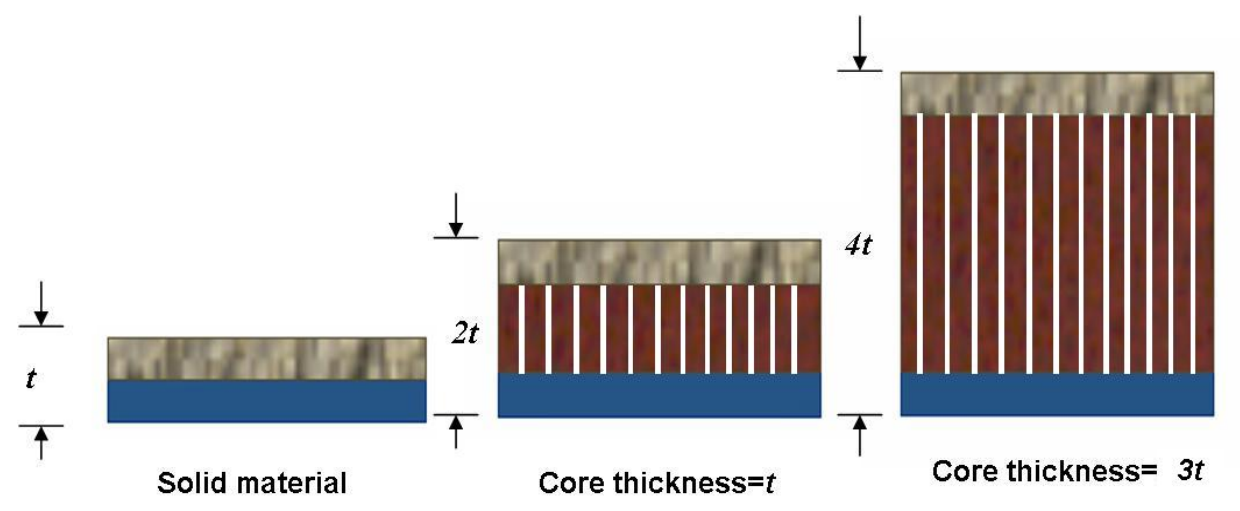

\begin{tabular}{|l|c|c|c|}
\hline Stiffness & 1 & 7 & 37 \\
\hline Flexural strength & 1 & 3.5 & 9.2 \\
\hline Weight & 1 & 1.03 & 1.06 \\
\hline
\end{tabular}

Figure (3): The relative stiffness and weight of sandwich panels compared to solid panels [7].

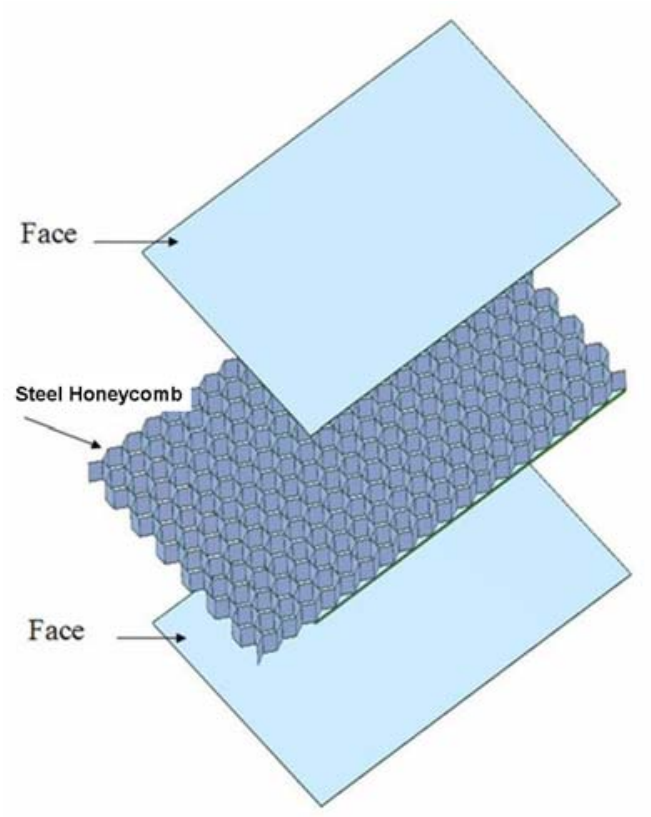

Figure (4): Three dimensional sketch of the steel hexagonal honeycomb sandwich panel. 


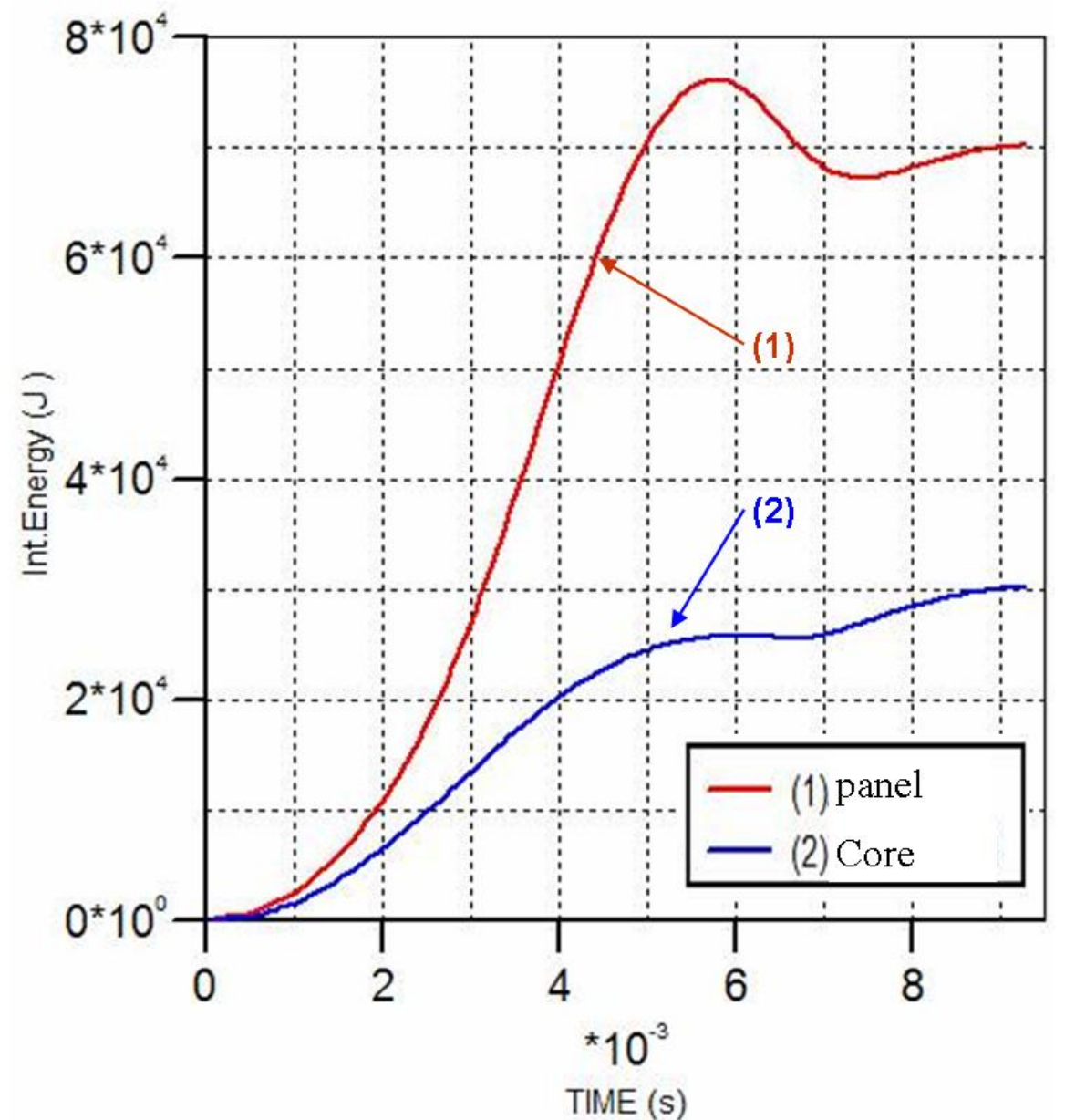

Figure (5): Internal energy absorbed by hexagonal core \& panel.

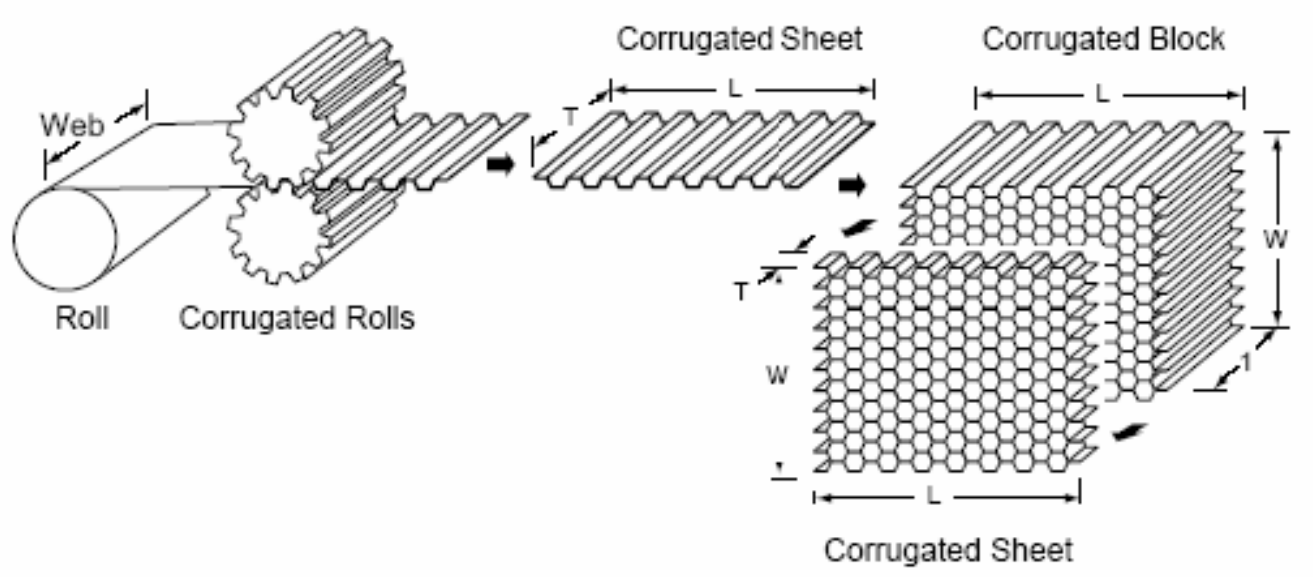

Figure (6): Corrugated process of honeycomb manufacture [5]. 

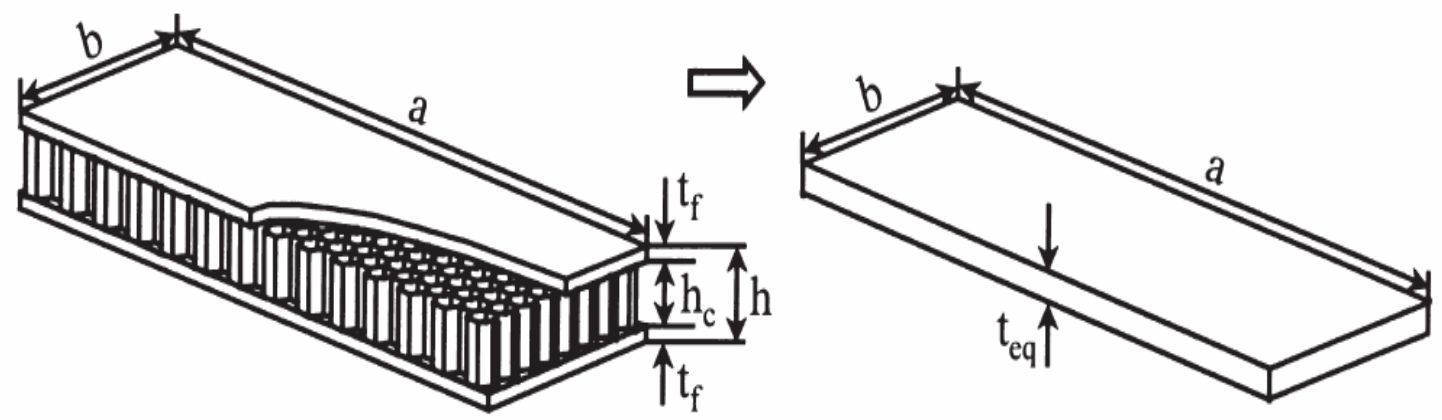

Figure (7): A schematic of the equivalent single skin approach [4].

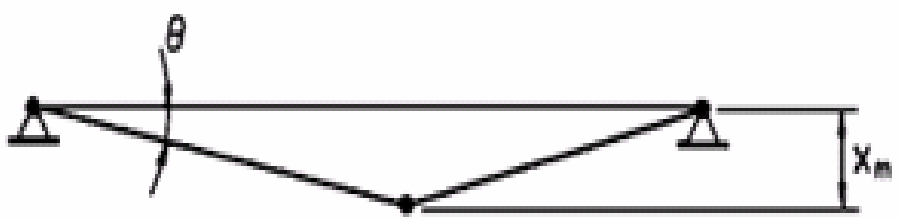

BEAM, SLAB OR PANEL

Figure (8): Schematic of plastic hinge [1].

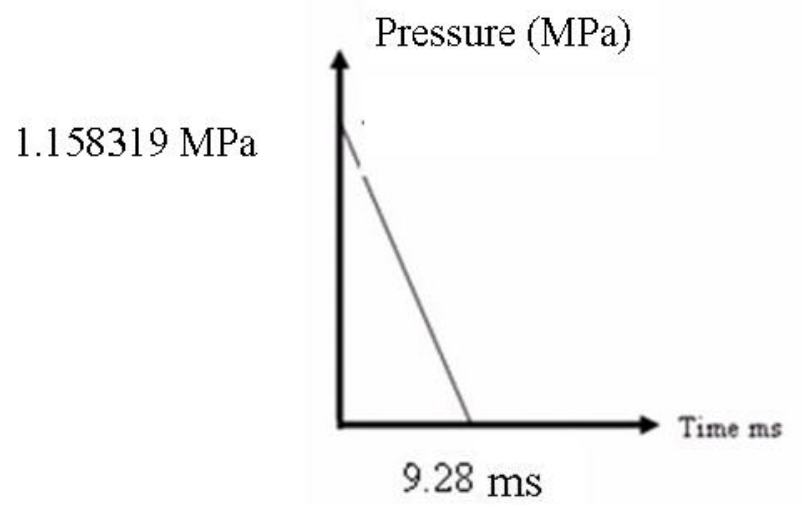

Figure (9): Approximate pressure time history (100 kg TNT at distance $5 \mathrm{~m}$ ). 


\begin{tabular}{|l|l|}
\hline MS2 & 13 \\
\hline
\end{tabular}

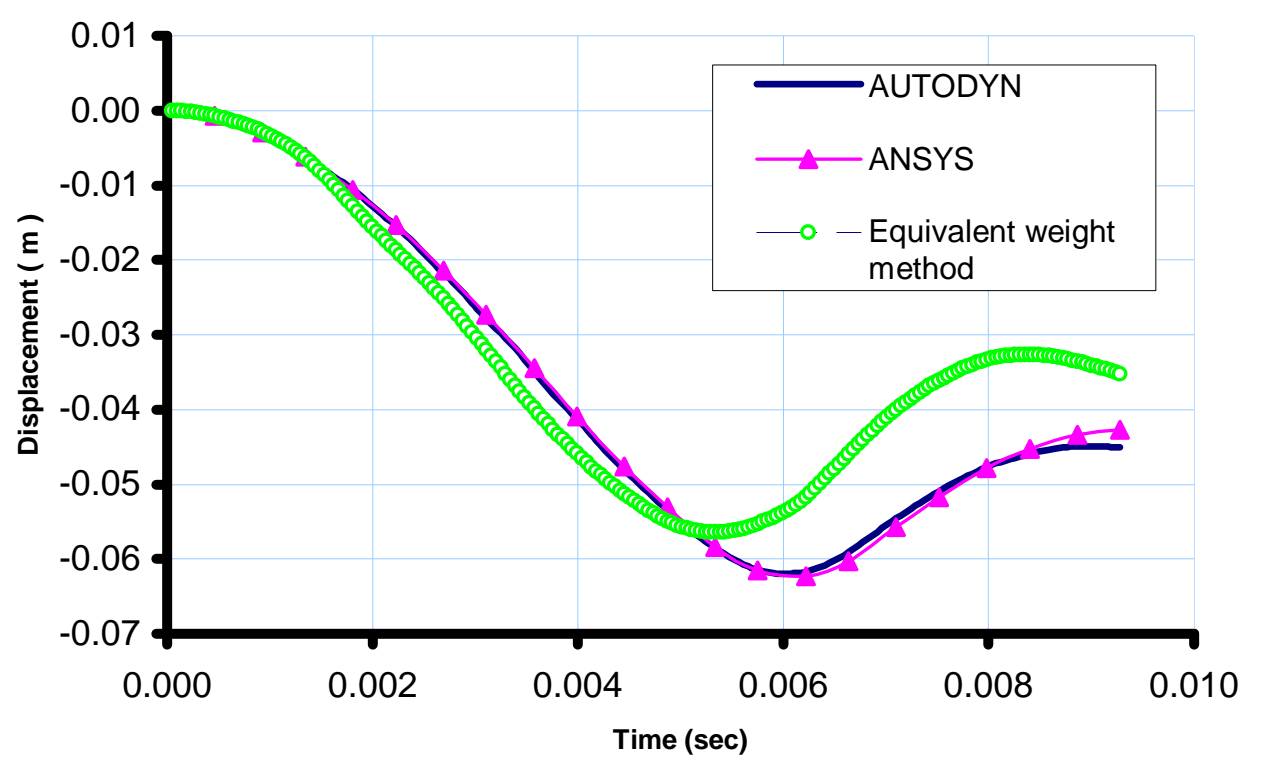

Figure (10): Time-deflection history obtained using AUTODYN and ANSYS at the location of maximum response.

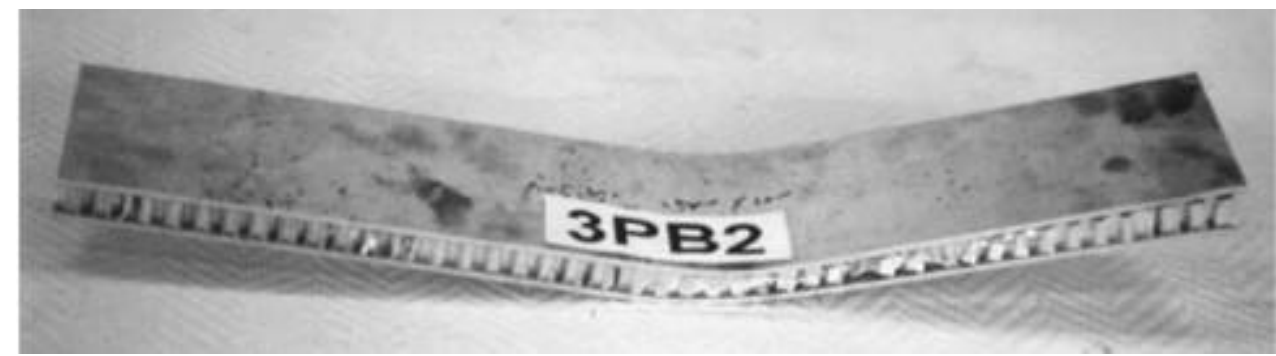

Figure (11): Deformed shape of the specimen 3PB2 after testing[4].
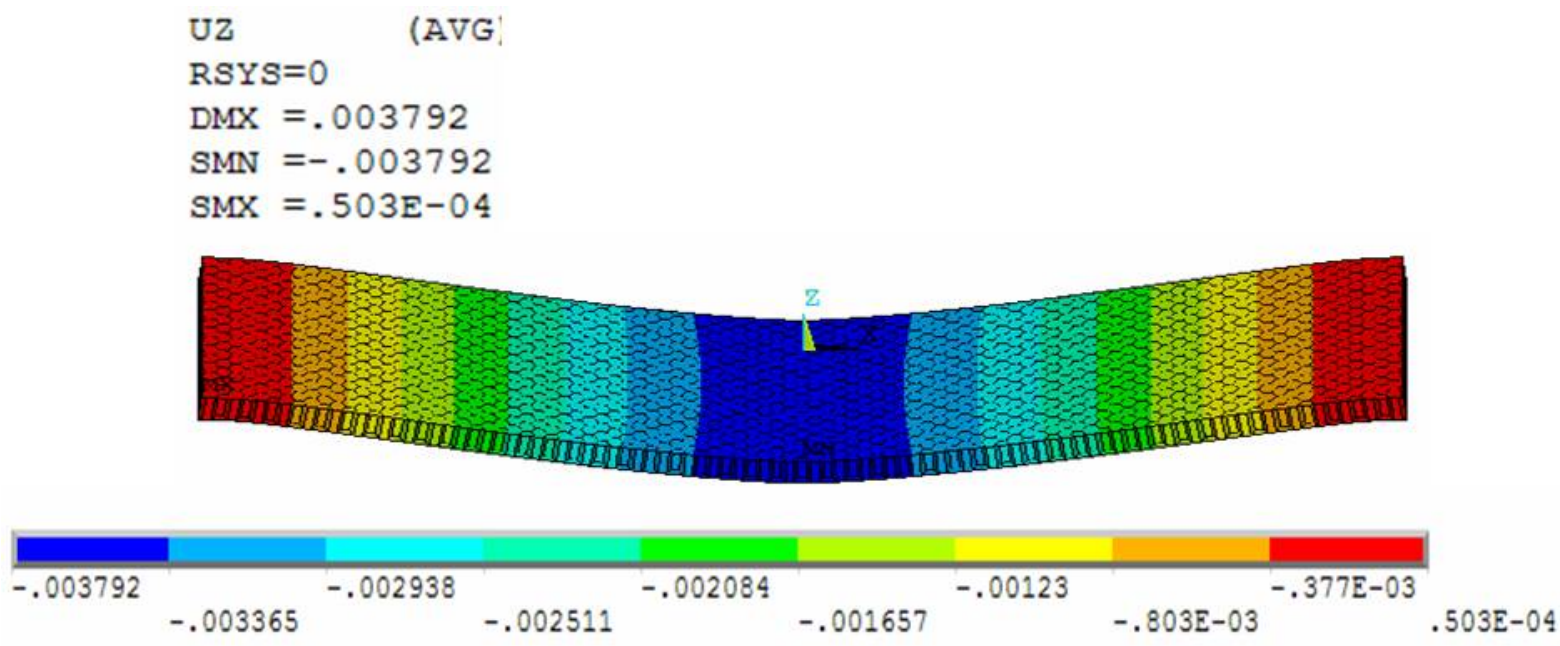

Figure (12): Deformed shape of the specimen in F.E. 


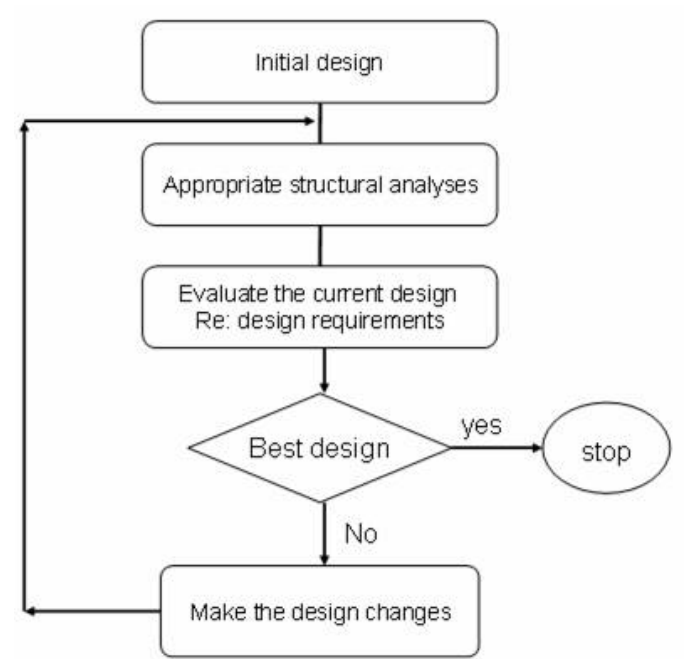

Figure (13): Optimal design flowchart [6].

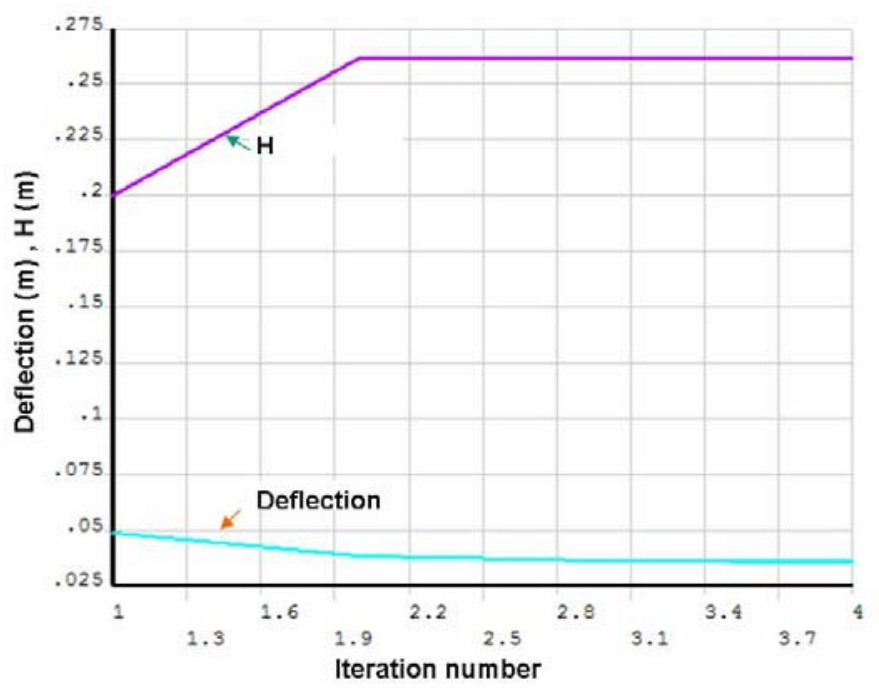

Figure (14): Maximum deflection and h versus iteration number.

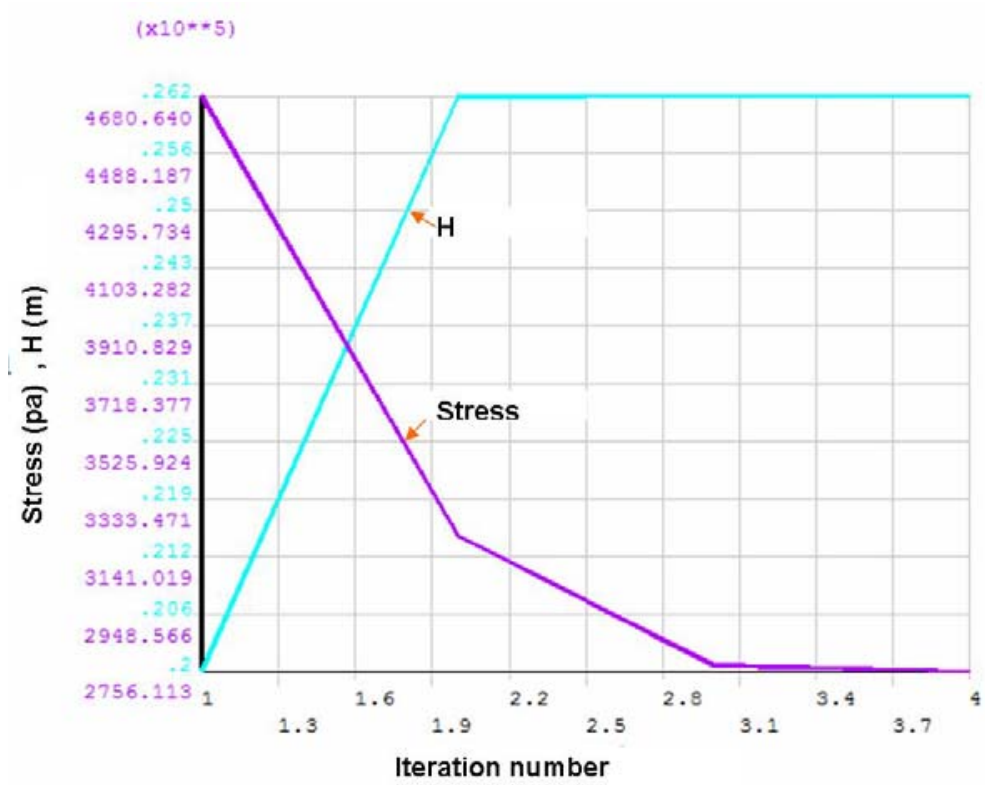

Figure (15): Stress and h versus iteration number. 


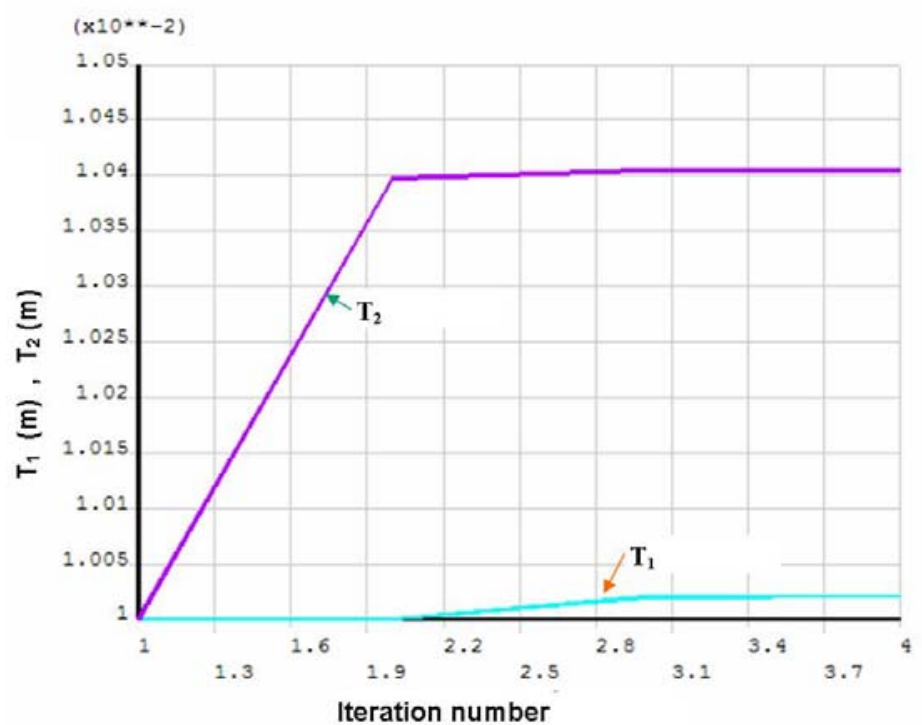

Figure (16): $\mathrm{T}_{1}$ and $\mathrm{T}_{2}$ versus iteration number.

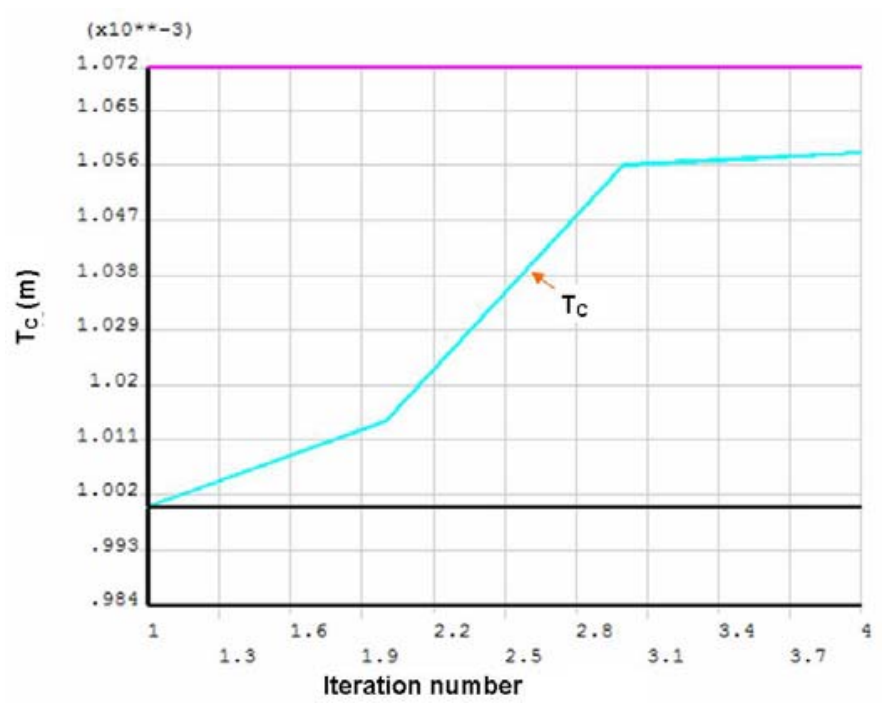

Figure (17): $T_{c}$. versus iteration number.

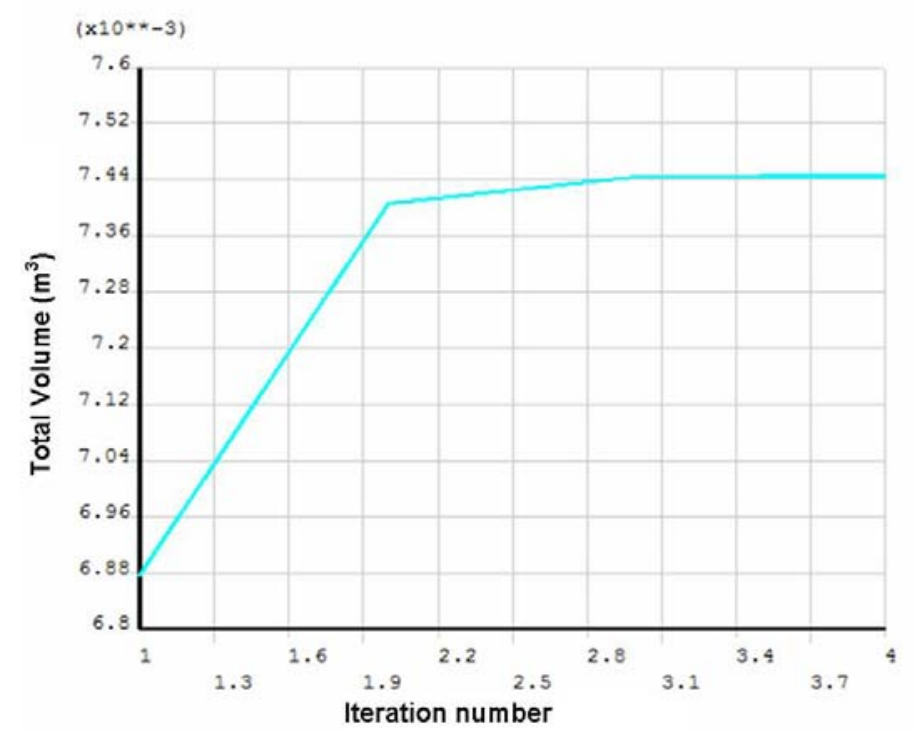

Figure (18): Volume. versus iteration number. 


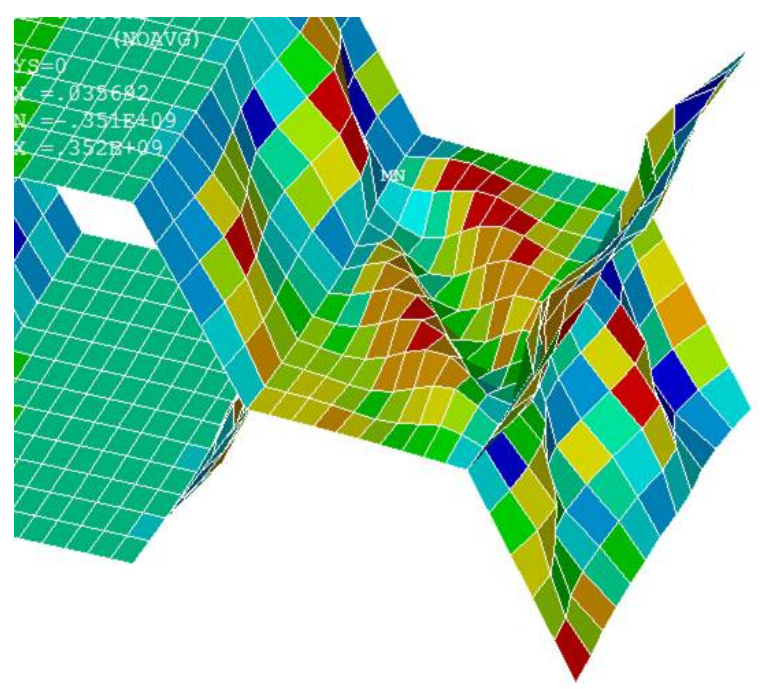

Figure (19): Deformation of the core (near support) at time $6.217 \mathrm{~ms}$.

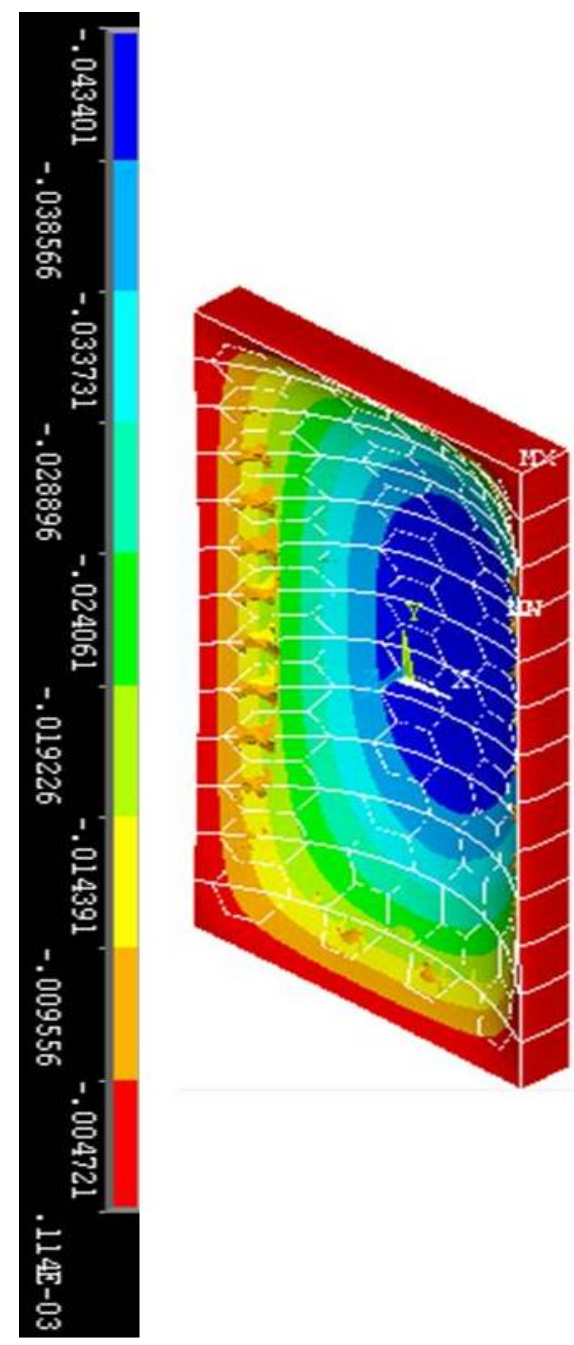

Figure (20): The deformation of the whole panel at $\mathrm{t}=6.217 \mathrm{~ms}$.

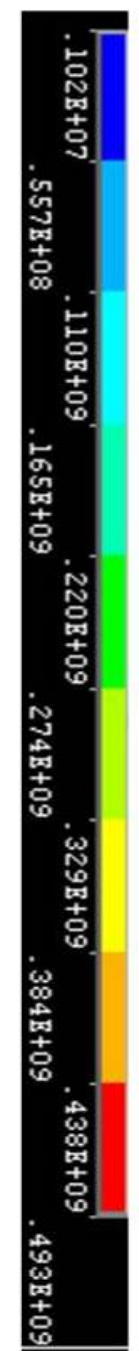

Figure (21): Stress distribution in total components of the panel at $\mathrm{t}=6.217 \mathrm{~ms}$. 


\begin{tabular}{|l|l|}
\hline MS2 & 17 \\
\hline
\end{tabular}

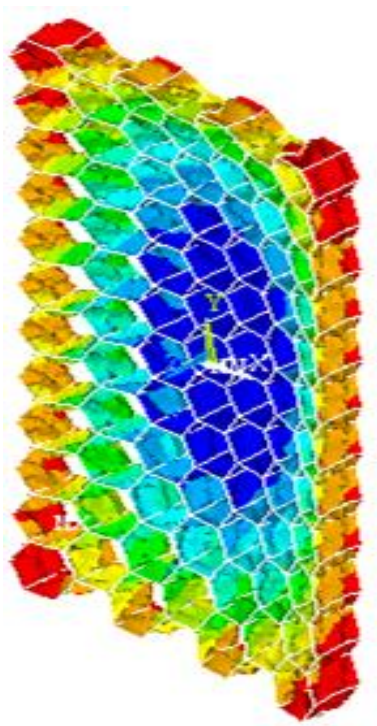

Figure (22): The deformation in hexagonal core, $\mathrm{t}=6.217 \mathrm{~ms}$.

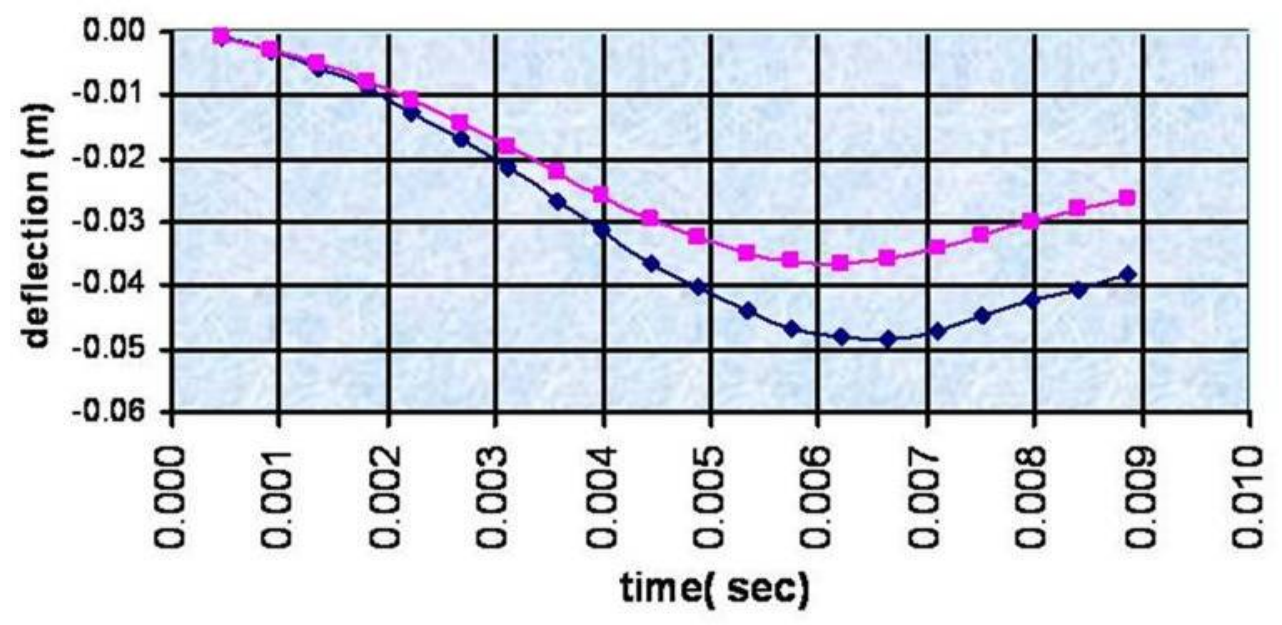

$\longrightarrow$ - befor-optimization $\rightarrow$ - after-optimization

Figure (23): Displacement-time history for target before and after optimization.
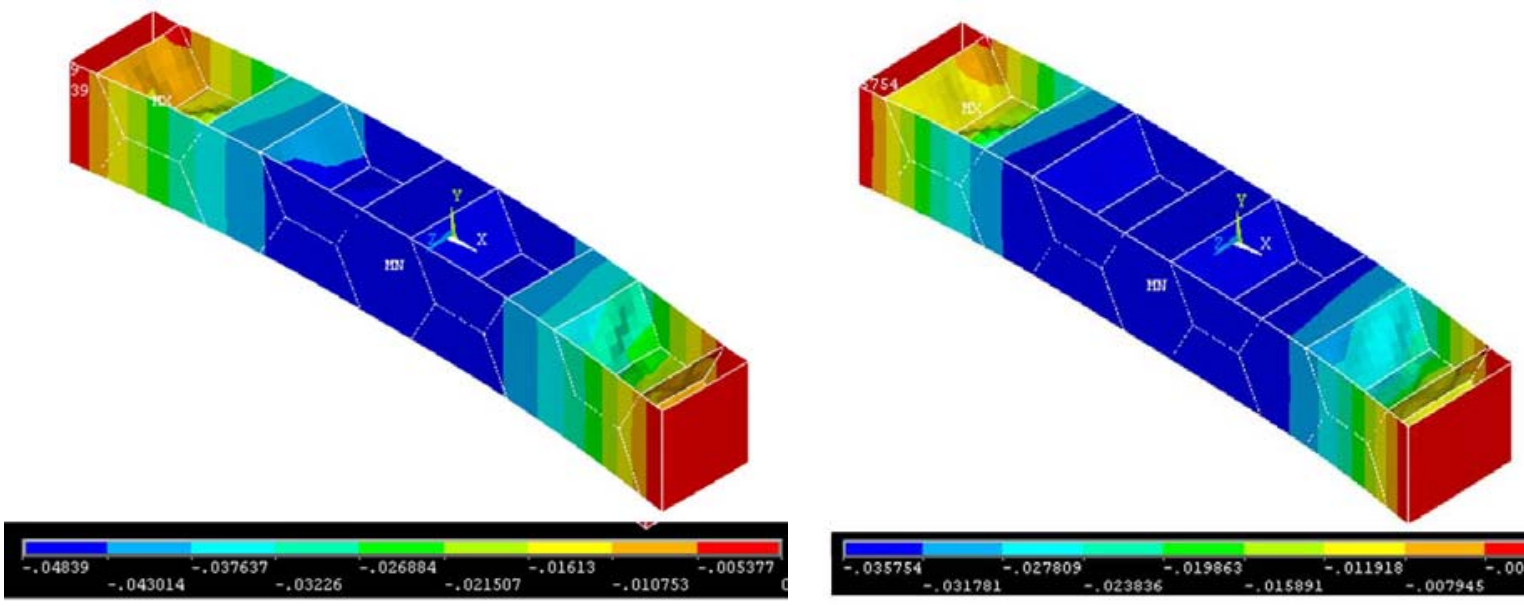

Figure (24): Deformation for the unit strip before (Left) and after optimization ( Right ).

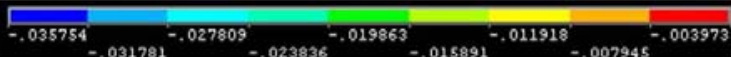




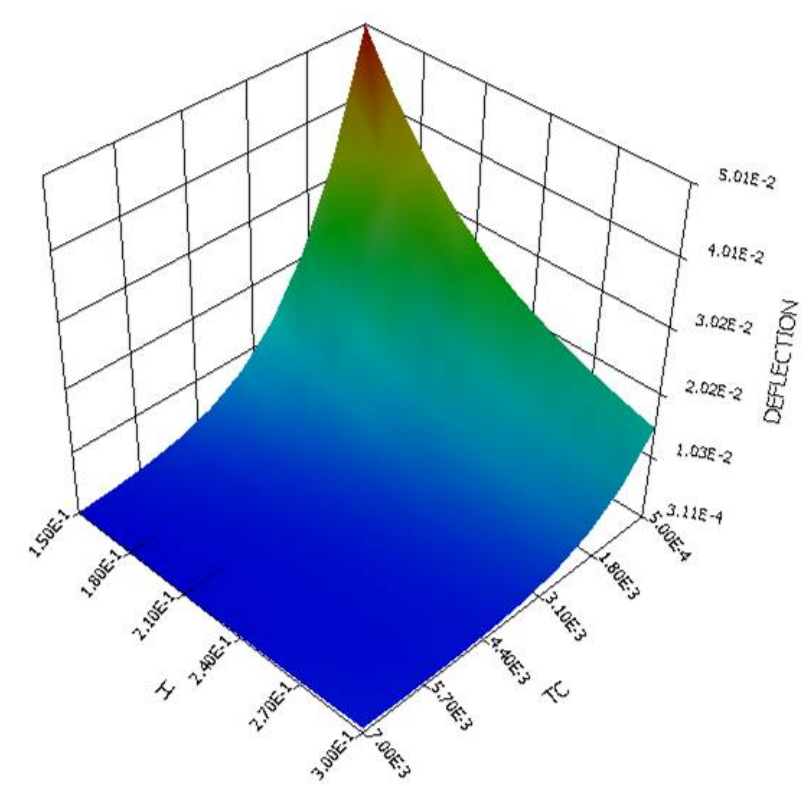

Figure (25): 3D-Plot of response surfaces ( $\mathrm{H}, \mathrm{T}_{\mathrm{C}}$, deflection ).

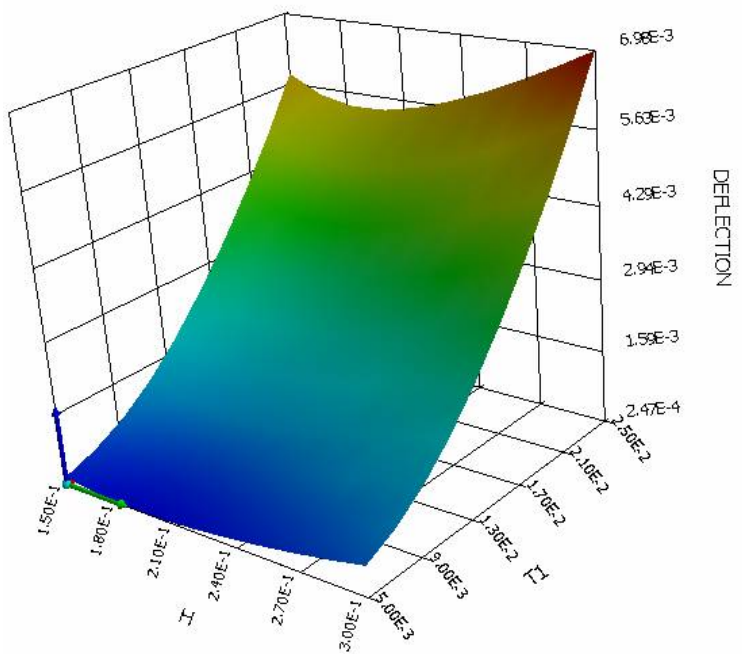

Figure (26): 3D-Plot of response surfaces ( $\mathrm{H}, \mathrm{T}_{1}$, deflection ).

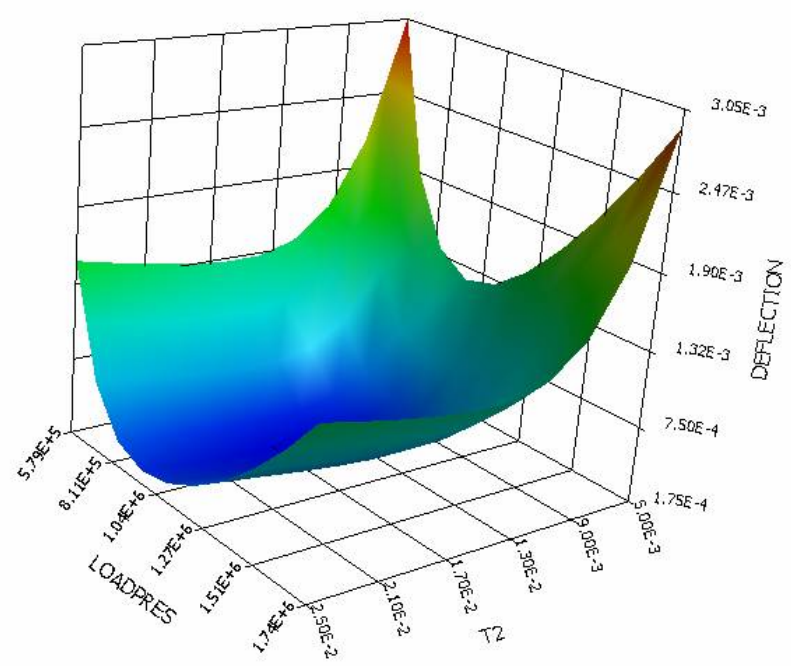

Figure (27): 3D-Plot of response surfaces ( load, $\mathrm{T}_{2}$, deflection ). 


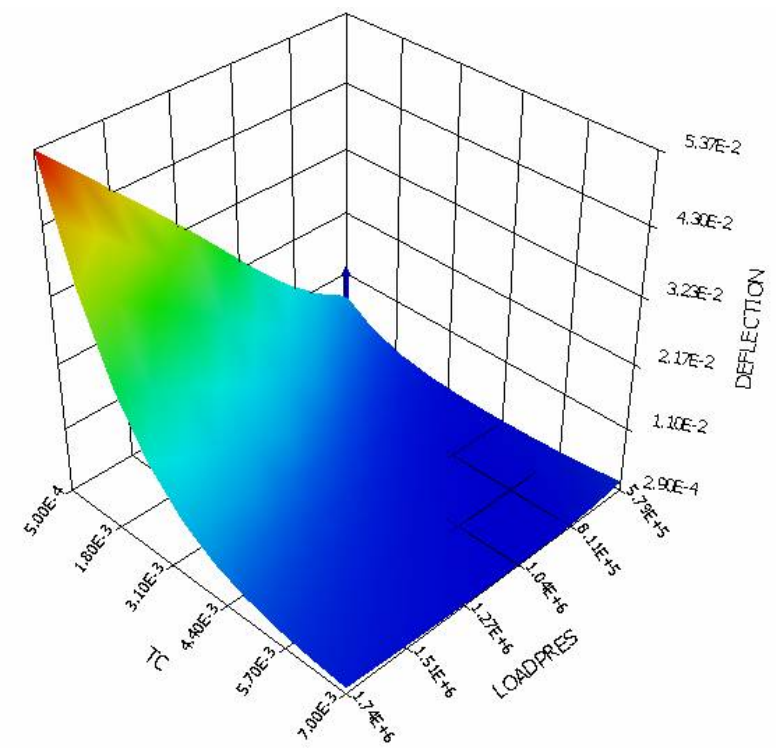

Figure (28): 3D-Plot of response surfaces ( load, $T_{c}$, deflection ).

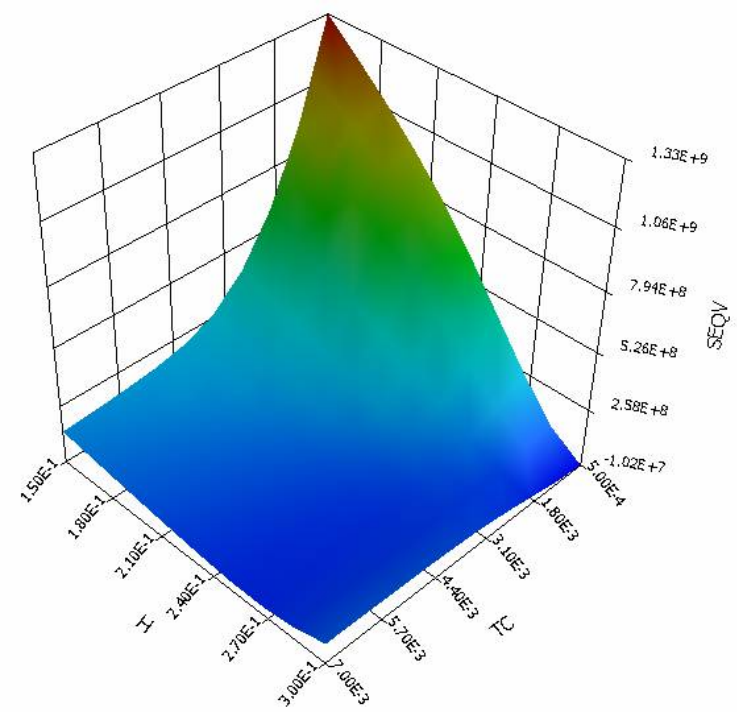

Figure (29): 3D-Plot of response surfaces ( $H, T_{c}$, stress ).

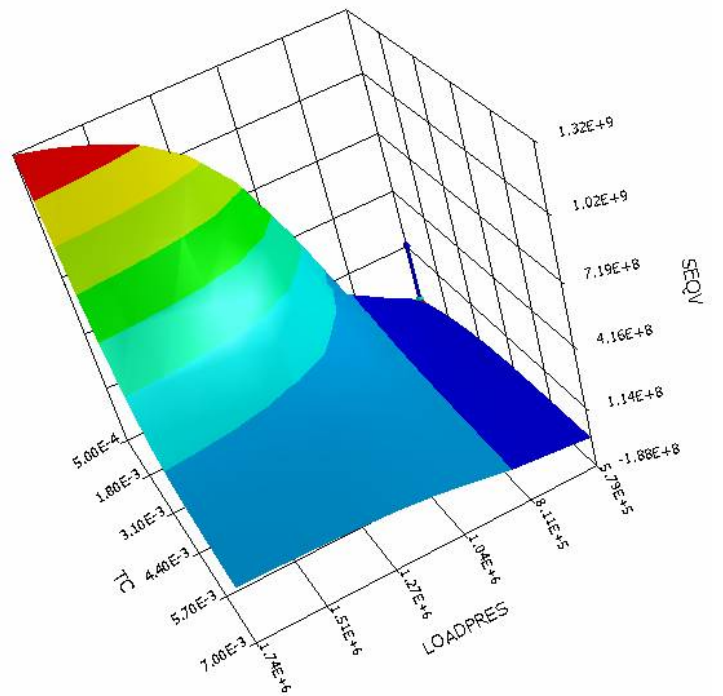

Figure (30): 3D-Plot of response surfaces ( load, $T_{c}$, stress ). 